\title{
PERCEIVED DISSUASIVENESS OF CIGARETTE HEALTH WARNING MESSAGES AMONG SMOKERS AND NONSMOKERS IN ANAMBRA STATE, NIGERIA
}

\author{
Chinedu Richard Ononiwu \\ Department of Mass Communication, \\ Nnamdi Azikiwe University, Awka \\ ononiwumartins@gmail.com

\section{Victor Agusiobo} \\ Department of Mass Communication, \\ Federal Polytechnic, Oko \\ agusiobo2v@gmail.com

\section{Sandra U. Ukwuru} \\ Department of Mass Communication, \\ Nnamdi Azikiwe University, Awka, \\ Anambra State \\ ukwuruugwo@gmail.com

\section{Prisca Nwankwo} \\ Department of Mass Communication, \\ Nnamdi Azikiwe University, Awka, \\ Anambra State \\ nwankwoprisca1@gmail.com
}

\section{Chikanne Joannes Ezeigbo}

Department of Mass Communication, Nnamdi Azikiwe University, Awka chika.ezeigbo@yahoo.com

\begin{abstract}
Findings from the 2012 Global Adult Tobacco Survey which is still the latest nationwide tobacco use research in Nigeria show that 5.6\% (4.7 million) Nigerian adults aged 15 years or older used tobacco products: $10.0 \%$ (4.2 million) men and 1.1\% (0.5 million) women. One of the strategies for the control of this rate of tobacco use is the mandatory text-only Health Warning Messages available on cigarette packs in the country. This study explored the perceived dissuasiveness of the Text-only Health Warning Messages on cigarette packs in Nigeriaand how smoking history can influence this perception. To achieve the set objectives, a mixed-method approach involving survey and Focus Group Discussion was adopted. The study analyzed data collected from a sample of 400 residents in Anambra State, Nigeria selected through simple random sampling and another 12 selected through snowballing, for Focus Group Discussion. Findings showed that the content of the Health Warning Message and smoking history were factors that could influence perceived dissuasiveness of cigarette Health Warning Messages. Additionally, the smokers were found to have become accustomed to the Text-only Health Warning Messages. Findings also showed that the smokers' perception was in line with their smoking behaviour. Stated differently, they did not perceive the Text-only Health Warning Message as dissuasive and have therefore continued to smoke. However, Graphic Health Warning Messages (GHWMs) were perceived as more dissuasive than the text-only messages by both smokers and nonsmokers. Therefore, it is recommended that the federal government should introduce Graphic Health Warning Messages and make them mandatory for cigarette packaging and advertisements.
\end{abstract}

Keywords: Perceived dissuasiveness, Health Warning Messages, cigarette packaging, 


\section{INTRODUCTION}

Tobacco use is dangerous, and this is evident in statistics that show that it ranks second among the major causes of adult death and diseases in the world, killing nearly 6 million people every year, a figure which is expected to rise to 10 million by 2020 (WHO, 2002; WHO, 2013). This situation means that modalities are to be fashioned to dissuade individuals from tobacco use by drawing their attention, first of all, to the inherent health risks of doing so.One of such moves was made by the World Health Organization (WHO) in May 2003 when it adopted the Framework Convention on Tobacco Control (FCTC), a groundbreaking public health treaty to controltobacco supply and consumption. The treaty contains a "labelling" element that requires health warning information to cover at least $30 \%$ of the principal display areas and, ideally, $50 \%$ or more on tobacco packaging.This warning information may take the form oftext, visual information, or a combination of the two. The World Health Organization's Framework Convention on Tobacco Control (FCTC) stresses the need for every person to be informed about the health consequences, addictive nature and mortal threat posed by tobacco consumption and exposure to tobacco smoke(WHO, 2003).

By November 2004, forty countries -the minimumnumber necessary to bring the FCTC into force had ratified thetreaty. On February 27, 2005, the FCTC became international binding law, requiring all countries that ratified it totake steps to abide by its provisions. Fong (2003) saw the FCTC as the beginning of an extraordinary era fortobacco control as it is anticipated that many countries all overthe world will implement important new policies, includingmore effective warning labels, restrictions on advertising and promotion, and increased tobacco taxation. By 2015, the implementation of pictorial warning policies had occurred in 77 countries and jurisdictions that are home to nearly 50\% of the world's population (Canadian Cancer Society, 2014).

According to the 2012 Global Adult Tobacco Survey, about 5.6\% (4.7 million) Nigerian adults, between the ages of 15 years and above, used tobacco products: $10.0 \%$ ( 4.2 million) men and $1.1 \%$ ( 0.5 million) women, hence the need fortobacco use control, bearing in mind the inherent dangers. One of the strategies for the control of tobacco use in Nigeria, showing that it is to an extent in compliance with the FCTC provision, is the mandatory text-only Health Warning Messages on cigarette packs. However, thereare questionsas to the effectiveness of these warning messages. For Odeyemi, Osibogun, Akinsete and Sadiq (2009), unfortunately, the envisaged results may not have been elicited. As if the text-only Health Warning Messages were not dissuasive enough, the scholars reported in a study of secondary school students in Lagos State that although up to $82 \%$ of them had been exposed to warnings against smoking, theydid not significantly influence their smoking decision.

As argued byAhmad, Jaafar, Musa andNaing (2001), for health warnings to be effective, they should be able to motivate smokers to quit as it is usuallyassumed that because health warnings are soimportant, smokers will find this information sointeresting and convincing, that, after reading it, theywill quit smoking. However, this envisaged hypodermic impact of warning messages on the dangers of cigarette smoking is not the case as its efficacy can be limited as found in the study conducted by Odeyemiet al. (2009). Therefore, this study aims to determine the perceived dissuasiveness of the available Health Warning Message on cigarette packs in Nigeria for an insight into why they may not have been dissuasive enough. 
DOI: doi.org/10.47851/naujocommed.v2i1.116

\section{STATEMENT OF THE PROBLEM}

According to the 2012 Global Adult Tobacco Survey, 5.6\% (4.7 million) Nigerian adults aged 15 years or older used tobacco products, hence the need to control tobacco use, due to its inherent dangers. One of the modalities for tobacco control in Nigeria, showing that the country is to an extent compliant with the FCTC provision, is the mandatory text-only Health Warning Messages on cigarette packs. However, arguments persist as to the effectiveness of these warning messages, andit has been found particularly thateven the inclusion of Graphic Health Warning Messages (GHWMs) on the packs and advertisement of cigarettes and the use of dissuasive words may not be a guarantee that smokers would quit smoking (Kessels, Ruiter\&Jansma, 2010; Mansour \&Bakhsh, 2017). Stated differently, the existence of the common text-only warning on cigarette packs in Nigeria which reads that 'The Federal Ministry of Health warns that smokers are liable to die young' may mean smokers have trained themselves to ignore and see it as mere 'paper stamp' and go ahead to lit their cigarette.

Unfortunately, there seems to be a lack of an accumulation of research evidence on the perceived dissuasiveness of the available 'Text-only' Health Warning Message on cigarette packs in Nigeria and factors that can influence this perception despite the attention the dangers of cigarette smoking has received from health practitioners, scholars and policymakers.

\section{OBJECTIVES OF THE STUDY}

In precise terms, this study was aimed at the following:

1. To find out the proportion of smokers and nonsmokers in Anambra State, Nigeria who are aware of Health Warning Messages on cigarette packs.

2. To determine how smokers and nonsmokersin Anambra State, Nigeria perceive Health Warning Messages on cigarette packs to be dissuasive.

3. To ascertain the influence of smoking history on perceived dissuasiveness of Health Warning Messages on cigarette packs among smokers and nonsmokers in Anambra State.

\section{WARNING MESSAGES ON DANGERS OF CIGARETTE SMOKING: HOW DISSUASIVE?}

All things being equal, Health Warning Messages are meant to be dissuasive enough, communicating health risks to individuals to elicit a change of unhealthy behaviour. For Hammond, Fong, McNeill, Borland and Cummings (2006) and Hammond (2011) health warnings on cigarette packs provide a compelling and prominent source of health information for effective communication of specific disease risks. These warnings have evolved through several stages over the past four decades- from simple, vague messages placed on the side of cigarette packs, to messages on the front of the packs which focus on specific health effects, often accompanied by colour pictures (Hiilamo, Crosbie, \&Glantz, 2014).Kees, Burton, Andrews and Kozup (2006) see warnings and disclosure information which can inform consumers about the risks and potential dangers related to its usage as a counterbalance for the positive consequences derived from effective package design and other promotion.

The dissuasive effects of warning messages on the dangers of cigarette smoking have been the focus of some studies. One of such asconducted by Hammond, Fong, McNeill, Borland and Cummings (2006) showed that smokers who reported that they noticed warnings were between 1.5-3.0 times more likely to believe that smoking caused heart disease, 
DOI: doi.org/10.47851/naujocommed.v2i1.116

impotence and lung cancer. These findings give credence to communication models that suggest that attention is a critical early process in the attitude and behaviour change process. The ability of a message to, first of all, draw attention may go a long way in determining its effectiveness. For example, McGuire's (1989) persuasion model suggests that the earliest steps to persuasion consist of exposure and attention to a message. This is to say that if a message is successful in the early-stage processes, later-stage processes which involve attitude and behaviour change may occur, and conversely, when there is no exposure and attention, a message will fail to have its intended impact.

Findings from otherscholarssuggest that graphic warnings in the form of pictures and imagery can be more effective than text-only messages at communicating health risks by increasing perceptions of the harm of smoking, reducing the desirability of purchasing cigarettes, increasing negative affective reactions to smoking cues and improving recall for other health information (Fong, Hammond \&Hitchman, 2009; Hammond, 2009; Fathelrahman, Omar, Awang, Borland \& Fong, Hammond\&Zain, 2009;McCool, Webb, Cameron \&Hoek, 2012; Thrasher, Rousu, Hammond, Navarro \& Corrigan, 2011;Peters, Romer, Slovic, Jamieson, Wharfield, Mertz\&Carpenter, 2007; MacKinnon \&Fenaughty, 1993; Strasser, Tang, Romer, Jepson \& Cappella, 2012).

The focus of some other studies has been on the perceived effectiveness of Health Warning Messages. One of such as carried out by Adebiyi, Uchendu, Bamgboye, Ibitoye and Omotola (2016) explored the perceived effectiveness of graphic health warnings as a deterrent for smoking initiation among adolescents in selected schools in southwest Nigeria. Findings from the study showed that a pictorial image which depicted that 'cigarette causes cancer of the airways' evoked fear in $307(56.4 \%)$ of the respondents and that which depicted that "cigarettes causes impotence" evoked fear in 228 (41.9\%) respondents. In addition, the pictorial image depicting that "cigarette smoke harms children" evoked fear in $215(39.5 \%)$ while that which depicted that "cigarettecauses stroke" evoked fear in $203(37.3 \%)$ respondents. Similarly, Images 1, 2, 3, and 4 shocked 203 (37.3), 148 (27.2), 179 (32.9) and $127(23.3 \%)$ respondents respectively. Anxiety was also evoked by the images with $16(2.9)$, 115 (21.1), 107 (19.7) and $80(14.7 \%)$ respondents expressing that they felt this on seeing Images 1, 2, 3 and 4 respectively. Findings from the study also showed that a significantly higher proportion of students less than 15 years $(80.1 \%)$ perceived the images that depict that cigarette causes cancer of the airways was to a large extent, probably effective in preventing smoking initiation compared to those who were 15 years and older $(72.3 \%)$. The difference was statistically significant at $p=0$. 032. Similarly, students less than 15 years $(66.2 \%)$ significantly perceived Image 4 from France depicting that cigarette causes impotence as being to a large extent, probably effective in preventing smoking initiation compared to $57 \%$ who were 15 years and older $(p=0.03)$. The researchers added that gender did not significantly influence the respondents' perception of the likely effectiveness of any of the graphic health warnings. This result suggests that Health Warning Messages on the dangers of cigarettes are likely to promote more negative and less positive attitudes and perceptionstowards smoking. However, changes in attitudes do not always translate into changes in behavioural intention which modern attitude-behaviour models assume is critical for attitudes to influence behaviour (Fishbein\&Ajzen, 2010). Unfortunately, in some cases, the effects of Health Warning Messages are so watered down that they may not even change intention or decision let alone behaviour, and worse still, the effect may backfire. 
DOI: doi.org/10.47851/naujocommed.v2i1.116

As early as 1976, the evidence that exposure to antismoking communications could have the unintended consequence of increasing smoking-related intentions, an effect that can be described as a 'boomerang effect', was documented(Rogers \&Mewborn, 1976), and it is on this basis that some scholars have argued against graphic warnings (Ruiter\&Kok, 2005). Boomerang effect shows how smokers disengage from antismoking messages more than nonsmokers (Kessels, Ruiter\&Jansma, 2010) and become more critical of the message content (Freeman, Hennessy \&Marzullo, 2001). The evidence of a boomerang effect shows smoking history and individual differences as factors that can determine the dissuasive effect of health warning messages. This is also the same for perceived dissuasiveness. In a study conducted by Mansour and Bakhsh (2017), smokers generally perceived labels as significantly less effective compared with former smokers and nonsmokers.

Such factors as the content of the warning messages, in particular,havealso been shown to determine their effectiveness and perceived dissuasiveness. In two Nigerian studies, for instance, one reported that text-only warning messages had no significant effect on the smoking decision of $82 \%$ of the respondents (Odeyemi, Osibogun, Akinsete\&Sadiq, 2009) while the other, in which the respondents' were exposed to Graphic Health Warning Messages, showed that they inspired fear, anxiety and a perception of a probable dissuasiveness of the messages among them (Adebiyi, Uchendu, Bamgboye, Ibitoye\&Omotola, 2016).

In a study elsewhere, Mutti, Reid, Gupta, Pednekar, Dhumal,Nargis, Hussain and Hammond (2016) examinedthe perceived effectiveness of text and pictorial smokeless tobacco health warnings in India and Bangladesh, including different types of message content. Findings from the study showed that text-only warnings were perceived as less effective than all of the pictorial styles $(\mathrm{p}<0.001$ for all). Graphic warnings, on the other hand, were given higher effectiveness ratings than symbolic or testimonial warnings $(\mathrm{p}<0.001)$. In a similar study, Mansour and Bakhsh (2017) found that overall, the labels that had graphic images of illness or pathology were perceived to be most effective. However, some Text-only Health Warning Messages have been found to be perceived as more effective than others. Findings from a study conducted by Ahmad, Jaafar, Musa and Naing (2001) showed that the message 'smoking during pregnancy can harm your baby' and 'tobacco can harm your children' obtained the highest scores, with mean scores of 3.26 and 3.11, respectively, while the messages 'cigarettes are addictive' and 'smoking is forbidden' were perceived as the least effective with mean scores of only 2.33 and 2.22 respectively.

\section{THEORETICAL FRAMEWORK: SELECTIVE PERCEPTION}

The evidence of selective perception as drawn from media studies suggests that audience can consciously or unconsciously view aspects of information in such a way thatfavours them at the expense of those viewed as distracting, unimportant, or insignificant. This evidence shows a heterogeneous media audience, who belong to different socio-economic strata, perceiving the same message differently, in line with their disposition(Ekwenchi\& Ononiwu, 2021).

The selective perception theory does well to explain why individuals, after exposure to the same kind of messages, cannot toe the same line of perception. Anaeto, Onabajo and Osifeso (2008) write that selective perception is the tendency for people's perception to be influenced by wants, needs, attitudes and other psychological factors, meaning that different people can react to the same message in different ways. Okunna and Omenugha (2012) argue that when 
DOI: doi.org/10.47851/naujocommed.v2i1.116

people are exposed to mass media messages, they tend to interpret them to suit their existing attitudes, preconceptions, and predispositions. However, scholars like Ekwenchi and Ononiwu (2021) have raised questions regarding what happens after audience perception of media messages. They argue that individuals' behaviour may be different from their perception after their study which showed that some women had negative perception toward 'whitevertised' skincare products but went on to use them.

Due to the tendency of the audience to have diverse perceptions after exposure to the same type of messages, smokers and nonsmokers in Anambra State, Nigeria are likely to have different perceptions towards Health Warning Messages on cigarette packs. These perceptions are likely to vary with such demographic variables as the smoking history of the respondents.

\section{METHODOLOGY}

The study adopted a mixed-method approach of survey and Focus Group Discussion. For the survey, multi-stage random sampling was used to select 400 respondents aged 18 and above from as many households intwosenatorial districts in Anambra State -AnambraCentral and Anambra North.A structured questionnaire was designed for data collection and a pilot study was conducted to test its validity and reliability.

For qualitative data, Focus Group Discussion was conducted in two groups of six participants each. The sessions held in Awka, Anambra State on January 6, 2019 (for Group 1) and February 10, 2019 (for Group 2). Group 1 consisted of participants who stated they have smoked more than 100 cigarettes (heavy smokers) gathered through the snowball technique, where one contact (gotten from a bar) generated further contacts. They were all men as the snowball technique did not draw any woman. Group 2 consisted of three male and three female nonsmokers who were also gathered through the snowball technique. The discussion in the two groups lasted one hour and the participants were also exposed to packs of two cigarette brands common in Nigeria-Dorchester and Benson and Hedges. In addition, the participants in the two groups were exposed to two images with the captions 'Cigarette causes neck cancer' and 'Your smoke harms me' which were obtained from the pictorial health warning galleries of the World Health Organization.

\section{RESULTS}

Results from the survey of a sample of 400 respondents selected from as many households in Anambra North and Anambra Central senatorial districts as well as Focus Group Discussion involving two groups of six participants each are as follows:

\section{Response Rate for Survey}

Four hundred copies of the questionnaire were distributed with the help of 10 research assistants; $400(100 \%)$ were successfully recovered. Hence, a 100\% response rate was recorded.

\section{Demographic Variables}

Of the participants responding to demographic questions, $42 \%(\mathrm{n}=168)$ were females while $58 \%(n=232)$ were males. 23\% $(n=98)$ fell within the age bracket of $18-24 ; 47 \%(n=188)$ fell within the age bracket of 25-30;17\% $(n=68)$ fell within 31-39; and 13\% $(n=52)$ fell within the age bracket of 40 and above. Furthermore, 10\% ( $n=40)$ of the participants had no formal education; 26\% $(n=104)$ of the participants had First School Leaving Certificate as their 
DOI: doi.org/10.47851/naujocommed.v2i1.116

highest qualification; 34\% $(\mathrm{n}=136)$ had Senior School Certificate/Equivalent, and 5\% $(\mathrm{n}=20)$ had NCE/OND; while 20\% ( $\mathrm{n}=80)$ had First degree/HND as their highest qualification and $5 \%(\mathrm{n}=20)$ had postgraduate degrees.

With regards to smoking history, $4 \%(\mathrm{n}=16)$ of the respondents described themselves as occasional smokers (less than 50 cigarettes) while $1 \%(n=4)$ and $3 \%(n=12)$ described themselves as 'moderate' (less than 100 cigarettes) and'heavy'smokers (more than 100 cigarettes) respectively.In addition, $92 \%(\mathrm{n}=368)$ of the respondents described themselves as nonsmokers. This result means that $8 \%(n=32)$ of the respondents have smoked a cigarette, a figure whichis arguably high considering the statistics of tobacco use-related deaths and diseases according to WHO (2013). Of the respondents who have smoked a cigarette, only 1 was female while 31 were males.

The respondents were asked about their awareness of the text-only Health Warning Message on cigarette packs and advertisement in Nigeria that reads 'The Federal Ministry of Health Warns that Smokers are Liable to Die Young'. Data showed that of the 400 respondents, 44.8 $\%(n=179)$ stated they were aware of this message, while $55.3 \%(n=221)$ stated otherwise. This result suggests that the level of awareness on the Health Warning Message in Anambra State is low.

Regarding respondents' source of awareness of the text-only Health Warning Message available on cigarette packs in Nigeria, majority of the respondents who reported that they were aware of the health warning message $(57.0 \% ; \mathrm{N}=102)$ stated cigarette packs as their source of awareness. This was followed by the $26 \%(\mathrm{~N}=14.5)$ that stated television health programmes and the $8.9 \%(\mathrm{~N}=16)$ that stated Internet advertisements. This result which shows that cigarette packs are the respondents' main source of awareness on the Health Warning Message on cigarette packs in a way explains why majority of the respondents are unaware of this message. It would take a dealer on cigarettes, a smoker (irrespective of smoking history), and a curious nonsmoker to be aware of this health warning message.

Table 1:Perception of Text-only Health Warning Message as True

\begin{tabular}{lcc}
\hline & Frequency & Percent \\
\hline Yes & 361 & 90.5 \\
No & 39 & 9.5 \\
\hline Total & 400 & 100.0 \\
\hline
\end{tabular}

The respondents were asked about their perception of the text-onlyHealth Warning Message as true. This message as found on Dorchester cigarette packs waspresented to the respondents who stated that they were not aware of it to draw their responses on perception. Data in Table 1 show that $90.5 \%(n=361)$ perceived the text-only health warning message on cigarette packs in Nigeriaas true while $9.5 \%(n=39)$ did not perceive it so. This result suggests that the text-only message warning that smokers are liable to die young is seen as untrue by the majority of the respondents and this may be the basis of its ineffectiveness.

Table 2: Respondents' Perception of Text-only Health Warning Message as able to draw Attention

\begin{tabular}{ccc}
\hline & Frequency & Percent \\
\hline Yes & 360 & 90 \\
No & 40 & 10 \\
& & \\
& ORexCommpan2021 &
\end{tabular}


Volume 2 Number 1 Jan-Mar Issue

Data in Table 2 show that while 90\% $(\mathrm{n}=360)$ of the respondents perceived the text-only Health Warning Message on cigarette packs found in Nigeria as likely to draw attention, 10\% $(n=40)$ of them do not perceive it so. This result suggests that this message is catchy enough to initiate the process of behaviourand intention change.

Table 3: Respondents' Perception of Text-only Health Warning Message as Likely to Make Smokers Quit

\begin{tabular}{lcc}
\hline & Frequency & Percent \\
\hline Yes & 182 & 45.5 \\
No & 218 & 54.5 \\
\hline Total & 400 & 100.0 \\
\hline
\end{tabular}

The respondents were asked about their perception of the text-only Health Warning Message as likely to make smokers quit their habit. Data in Table 3 show that $45.5 \%(n=182)$ perceive it as likely to make smokers quit, while $54.5 \%(\mathrm{n}=218)$ do not perceive so. This result suggests that majority of the respondents perceived that a smoker's behaviour would override the dissuasiveness of the text-only message.

Table 4: Respondents' Perception of Text-only Health Warning Message as Likely to Dissuade Nonsmokers

\begin{tabular}{ccc}
\hline & Frequency & Percent \\
\hline Yes & 372 & 93 \\
No & 28 & 7 \\
\hline Total & 400 & 100.0 \\
\hline
\end{tabular}

The respondents were asked about their perception of the text-only Health Warning Message as likely to dissuade nonsmokers from picking the habit of smoking. The result shows that 93\% of them perceive the Health Warning Message as likely to do so; while $7 \%$ perceived otherwise. This result suggests that majority of the respondents are of the view that the Health Warning Message is effective enough to dissuade a nonsmoker from picking the habit of smoking more than it can make a smoker quit.

Table 5: Perception of Graphic Health Warning Messages (GHWMs) as Likely to Draw Attention

\begin{tabular}{cccc}
\hline & Frequency & Percent \\
& Yes & 388 & 97 \\
No & 12 & 3 \\
\hline Total & 400 & 100.0 \\
\hline
\end{tabular}

The participants were asked about their perception of the Graphic Health Warning Messages(GHWMs) presented to them as likely to draw attention. Table 5 indicates that $97 \%$ of them perceived the GHWMs as likely to draw attention, while 3\% do not perceive it so. This result suggests that majority of the respondents perceived the graphic Health Warning Message as able to draw more attention than the text-only Health Warning Message found on cigarette packs in Nigeria. 
Table 6: Perception of GHWMs as Likely to Make Smokers Quit

\begin{tabular}{ccc}
\hline & Frequency & Percent \\
\hline Yes & 293 & 73.5 \\
No & 79 & 19.5 \\
Sometimes & 28 & 7 \\
\hline Total & 400 & 100.0 \\
\hline
\end{tabular}

The respondents were also asked about their perception of the GHWMs as likely to make smokers quit. Data in Table 8 show that $73.5 \%$ of them perceive the GHWMs as dissuasive enough to make smokers quit, while $19.5 \%$ did not perceive so. In addition, $7 \%$ of the respondents were of the perception that the messages would make smokers quit sometimes. This result suggests that majority of the respondents view the GHWMs as more dissuasive than the text-only Health Warning Message found on cigarette packs in Nigeria with regards to making smokers quit their behaviour.

Table 7: Perception of GHWMsas Likely to Make Nonsmokers not Pick Habit

\begin{tabular}{lcc}
\hline & Frequency & Percent \\
Yes & 332 & 83 \\
No & 35 & 8.5 \\
Sometimes & 43 & 10.5 \\
\hline Total & 400 & 100.0 \\
\hline
\end{tabular}

Table 7 indicates that $83 \%$ of the respondents perceive the GHWMs as likely to dissuade nonsmokers from picking the habit of smoking. In addition, the table shows that $8.5 \%$ of them do not perceive themas likely to do so while $10.5 \%$ perceive them as likely to do so sometimes. This result suggests that majority of the respondents perceive the GHWMs to be as likely as the text-only Health Warning Messages to dissuade nonsmokers from picking the habit of smoking. It also suggests that nonsmokers are easier dissuaded than smokers.

Table 8: Smoking History and Perception of the text-only HWMto Draw Attention

Description of Smoking History

Total

\begin{tabular}{cccccc} 
& $\begin{array}{c}\text { Occasional } \\
\text { Smokers }\end{array}$ & $\begin{array}{c}\text { Moderate } \\
\text { Smokers }\end{array}$ & $\begin{array}{c}\text { Heavy } \\
\text { Smokers }\end{array}$ & $\begin{array}{c}\text { Nonsmoker } \\
\text { s }\end{array}$ & \\
\hline \multirow{2}{*}{ Yes } & 10 & 1 & 1 & 348 & 360 \\
& $62 \%$ & $25 \%$ & $8 \%$ & $94 \%$ & \\
\multirow{2}{*}{ No } & 6 & 3 & 11 & 20 & 40 \\
& $38 \%$ & $75 \%$ & $92 \%$ & $6 \%$ & \\
\hline \multirow{2}{*}{ Total } & 16 & 4 & 12 & 368 & 400 \\
\hline
\end{tabular}

Table 8 presents data on the relationship between the respondents' smoking history and perception of the text-only Health Warning Message would draw attention.As shown on the table, $62 \%(\mathrm{~N}=10)$ of the respondents who described themselves as occasional smokers 
DOI: doi.org/10.47851/naujocommed.v2i1.116

perceivethe text-only Health Warning Message as likely to draw attention. Of the respondents who described themselves as moderate smokers, $25 \%$ perceive the text-only Health Warning Message as likely to draw attention. In addition, only $8 \%$ of therespondents who described themselves as heavy smokers perceive the text-only Health Warning Message as likely to draw attention. For the respondents who described themselves as nonsmokers, 94\% perceive the text-only Health Warning Message as likely to draw attention. What this result suggests is that the more an individual smokes, the lesser the text-only Health Warning Message is perceived as likely to draw attention.

Table 9: Smoking History and Perception that text-only HWM can Make Smokers Quit

Description of Smoking History Total

$\begin{array}{cccc}\text { Occasional } & \text { Moderate } & \text { Heavy } & \text { Nonsmokers } \\ \text { Smokers } & \text { Smokers } & \text { Smokers } & \end{array}$

\begin{tabular}{cccccc}
\hline & 11 & 2 & 1 & 168 & 182 \\
Yes & $68 \%$ & $50 \%$ & $9 \%$ & $45 \%$ & \\
& 5 & 2 & 11 & 200 & 218 \\
No & $32 \%$ & $50 \%$ & $91 \%$ & $55 \%$ & \\
\hline \multirow{2}{*}{ Total } & 16 & 4 & 12 & 368 & 400 \\
\hline
\end{tabular}

Table 9 shows data on the relationship between respondents' smoking history and perception that the text-only Health Warning Message can make smokers quit smoking. Of the respondents who described themselves as occasional smokers, $68 \%$ perceive the message as likely to make smokers quit while $50 \%$ of those who described themselves as moderate perceive so. Only 9\% of the respondents who described themselves as heavy smokers perceive the text only message as likely to make smokers quit and for those who stated they were nonsmokers, $45 \%$ of them perceived so. What this result suggests is that the more an individual smokes, the less the text-only Health Warning Message is perceived as dissuasive enough to make smokers quit the habit. For the nonsmokers, it could be that they see smokers' behaviour as able to override the dissuasiveness of the text-only Health Warning Message so much it is unable to make them quit.

Table 10: Smoking History and Perception that text-only HWM can Dissuade Nonsmokers from Picking Habit

Description of Smoking History Total

$\begin{array}{cccccc} & \begin{array}{c}\text { Occasional } \\ \text { Smokers }\end{array} & \begin{array}{c}\text { Moderate } \\ \text { Smokers }\end{array} & \begin{array}{c}\text { Heavy } \\ \text { Smokers }\end{array} & \text { Nonsmoke } & \\ \text { Yes } & 12 & 4 & 3 & 353 & 372 \\ & 75 \% & 100 \% & 33 \% & 95 \% & \\ \text { No } & & & & & \\ & & & & & \end{array}$


Table 10 shows data on the relationship between respondents' smoking history and perception of the text-only Health Warning Message as likely to dissuade nonsmokers from picking the habit of smoking. Of the respondents who described themselves as occasional smokers, $75 \%$ perceive the text-only health warning message as likely to dissuade nonsmokers from picking smoking habit; while $100 \%$ of the respondents who described themselves as moderate smokers perceive so. Only 33\% of the respondents who described themselves as heavy smokers perceive the messages as likely to dissuade nonsmokers from picking the habit of smoking, while $95 \%$ of nonsmokers did so. This result suggests that it is easier for nonsmokers to be dissuaded from picking the habit of smoking by the text-only Health Warning Message than for smokers to quit. In other words, the text-only Health Warning Message is dissuasive enough to make nonsmokers not pick the habit but not to make smokers quit.

Table 11: Smoking History and Perception that GHWMs Can Draw Attention

\begin{tabular}{|c|c|c|c|c|c|}
\hline \multicolumn{6}{|c|}{ Description of Smoking History } \\
\hline & $\begin{array}{c}\text { Occasional } \\
\text { Smokers }\end{array}$ & $\begin{array}{l}\text { Moderate } \\
\text { Smokers }\end{array}$ & $\begin{array}{c}\text { Heavy } \\
\text { Smokers }\end{array}$ & Nonsmokers & Total \\
\hline Yes & $\begin{array}{c}16 \\
100 \%\end{array}$ & $\begin{array}{c}3 \\
75 \%\end{array}$ & $\begin{array}{c}11 \\
91 \%\end{array}$ & $\begin{array}{l}358 \\
97 \%\end{array}$ & 388 \\
\hline No & $\begin{array}{c}0 \\
0 \%\end{array}$ & $\begin{array}{c}1 \\
25 \%\end{array}$ & $\begin{array}{c}1 \\
9 \%\end{array}$ & $\begin{array}{l}10 \\
3 \%\end{array}$ & 12 \\
\hline Total & 16 & 4 & 12 & 368 & 400 \\
\hline
\end{tabular}

The respondents were exposed to two Graphic Health Warning Messages and Table 11 presents data on the relationship between their smoking histories and theirperception of these messages as likely to draw attention. The table shows that $100 \%$ of the respondents who described themselves as occasional smokers perceive the GHWMsas likely to draw attention; $75 \%$ of those who described themselves as moderate smokers perceived so. For those who described themselves as heavy smokers, $91 \%$ perceived the graphic health warning messages as likely to draw attention;while $97 \%$ of the respondents who described themselves as nonsmokers perceived so. What this result suggests is that the GHWMsare perceived to draw more attention than the text-only Health Warning Message.

Table 12: Smoking History and Perception that GHWMs can Make Smokers Quit Habit

\begin{tabular}{|c|c|c|c|c|c|}
\hline & \multicolumn{4}{|c|}{ Description of Smoking History } & \multirow[t]{2}{*}{ Total } \\
\hline & $\begin{array}{c}\text { Occasional } \\
\text { Smokers }\end{array}$ & $\begin{array}{l}\text { Moderate } \\
\text { Smokers }\end{array}$ & $\begin{array}{l}\text { Heavy } \\
\text { Smokers }\end{array}$ & Nonsmokers & \\
\hline Yes & 10 & 2 & 1 & 280 & 293 \\
\hline & ORexCc & & & & \\
\hline
\end{tabular}


NNAMDI AZIKIWE UNIVERSITY

Volume 2 Number 1 Jan-Mar Issue

Journal OF COMMUNICATION AND MEDIA STUDIES

DOI: $\underline{\text { doi.org/10.47851/naujocommed.v2i1.116 }}$

ISSN:2756-486X (Online)

\begin{tabular}{cccccc} 
& $62 \%$ & $50 \%$ & $8 \%$ & $76 \%$ & \\
No & 6 & 2 & 11 & 60 & 79 \\
& $38 \%$ & $50 \%$ & $92 \%$ & $16 \%$ & \\
Sometimes & 0 & 0 & 0 & 28 & 28 \\
& $0 \%$ & $0 \%$ & $0 \%$ & $8 \%$ & \\
& & & & & 368 \\
\hline Total & 16 & 4 & 12 & & 400 \\
\hline
\end{tabular}

The respondents were also asked about their perception of the GHWMsas likely to make smokers quit the habit. Table 12 shows that $62 \%$ of those who described themselves as occasional smokers perceived the Graphic Health Warning Messages (GHWMs) as likely to make smokers quit the habit; while $50 \%$ of those who described themselves as moderate smokers perceived so. In addition, only $1(8 \%)$ of the respondents who described themselves as heavy smokers perceived the GHWMsas likely to make smokers quitthe habit; while $76 \%$ of those who described themselves as nonsmokers perceived so. This result suggests that the GHWMsare perceived to be more likely to make smokers quit than the text-only Health Warning Message among most of the respondents. However, the contrary perception of most of those who described themselves as heavy smokers may have been borne out of experience.

Table 13: Smoking History and Perception that GHWMs can dissuade from Picking Habit

\begin{tabular}{cccccc} 
& \multicolumn{3}{c}{ Description of Smoking History } & Total \\
& Occasional & Moderate & Heavy & Nonsmokers & \\
Smokers & Smokers & Smokers & & \\
\hline Yes & 14 & 3 & 10 & 295 & 322 \\
& $87 \%$ & $75 \%$ & $83 \%$ & $80 \%$ & \\
No & 2 & 1 & 2 & 30 & 35 \\
& $19 \%$ & $25 \%$ & $17 \%$ & $8 \%$ & \\
Sometimes & 0 & 0 & 0 & 43 & 43 \\
& $0 \%$ & $0 \%$ & $0 \%$ & $12 \%$ & \\
\hline & 16 & 4 & 12 & 368 & 400 \\
\hline
\end{tabular}

The respondents were also asked about their perception of the GHWMs as likely to dissuade nonsmokers from picking the habit of smoking. Table 13 shows that $87 \%$ of respondents who described themselves as occasional smokers perceived the GHWMs as likely to dissuade nonsmokers from picking the habit of smoking; while $75 \%$ and $83 \%$ of those who described themselves as moderate and heavy smokers respectively perceived so. For those who described themselves as nonsmokers, $80 \%$ of them perceived the GHWMs as likely to dissuade nonsmokers from picking the habit of smoking. This result suggests that the GHWMs are once again perceived to be more effective than the text-only message, this time, with regards to dissuading nonsmokers from picking the habit of smoking. However, this 
DOI: doi.org/10.47851/naujocommed.v2i1.116

result may also mean that it is easier for the GHWMs to have a dissuasive effect on nonsmokers than smokers.

\section{Qualitative Data}

Five dominant themes emerged from the Focus Group Discussion conducted in the two groups. The analysis is laced with the exact words of the participants.

\section{Smokersare accustomed toText-only Health Warning Messages}

According to the participants in Group1 which is made up of smokers only, the Health Warning Message that reads that 'The Federal Ministry of Health Warns that Smokers are Liable to die young' as found on the packs of Dorchester and Benson and Hedgesis something they see every dayand have become accustomed to. They see this message as having no effect on them and go ahead to ignore it. 'I see those things as mere letters printed in black. The Federal Ministry of Health has to say something. We are now used to it' (Group $1, \mathrm{P} 3)$.

The participants in Group 2 also share the view that smokers have become accustomed to this message. 'I know say my friends no de even look the message. They just open the pack, draw their cigarette, and smoke. I think they have trained their eyes not to see this message' (Group 2, P1). What these responses suggest is that the text-only Health Warning Message has no effect on smokers.

\section{Health Warning Messages are exaggerated}

Majority of the participants in the Focus group perceive the Graphic Health Warning Messages (GHWMs)as exaggerated as they are yet to see anyone who looked like the graphics presented to them due to smoking:

I have smoked for 15 years and I think that is enough time for me to have experienced any effect of smoking. My lungs should have turned black by now or my throat looking like what you have in that picture (referring to the image with the caption cigarette causes neck cancer) (Groupl, P2)

Most of the participants in Group 2 also perceive the GHWMsas exaggerated. 'I have an uncle and his friend who their smoking is everyday. They look very fresh and young and they have smoked for as long as I know them' (Group 2, P1). 'I have not seen anybody whose throat lookslike that (referring to the image with the caption cigarette causes neck cancer) because he smokes. I think these messages are just to make people afraid' (Group 2, P2).

\section{Graphic Health WarningMessages are more likely to be effective}

The participants in Group 1 are of the perception that if any Health Warning Message is to be effective, it has to be the ones presented as graphics: 'this picture (referring to the image with the caption cigarette causes neck cancer) can make someone afraid. The person will just imagine himself looking like that and it may make him to stop smoking' (Group 1, P2). The view of one other participant suggests that the GHWMscan be so effective it can distort cigarette sales: 'cigarette manufacturers in Nigeria cannot use graphics on their cigarette 
DOI: doi.org/10.47851/naujocommed.v2i1.116

packs. They know it will just spoil their market. Imagine smoking and looking at any of these images' (Group 1, P3).

The participants in Group 2 also perceive the GHWMsas likely to be effective. 'These pictures fit put fear for pesinbodi. I mean they can make a smoker afraid. It is better they are used on cigarette packs instead of what we have now' (Group 2, P6).

\section{Quitting is hard for heavy smokers}

Majority of the participants perceive the text-only Health Warning Message as effective enough to dissuade a nonsmoker from picking up the habit of smoking or an occasional smoker from becoming addicted. They however shared the perception that the message is not dissuasive enough for heavy smokers. In the words of one of the participants in Group 1:

\section{'Like I said before, I am used to this message. To tell you the truth, a times I don't even look at it. Someone who has smoked for sometime and has not experienced any health issues like me cannot quit because of this message. Like my friend, I have smoked for, well, almost 15 years too' (Group 1, P1).}

The participants in Group 2 also share the view that the warning messages cannot dissuade smokers. 'Once somebody starts smoking, it is difficult to quit. It is better an individual does not start at all. If these messages were working, cigarette makers will go out of business, they will not be selling again' (Group 2, P5).

\section{DISCUSSION}

Of the 400 respondents who participated in the survey, $8 \%(n=32)$ have smoked a cigarette. This result is worrisome as far as tobacco-related deaths and diseases are concerned and could be an indication that there is an increase in the percentage of adults who use tobacco products in Nigeria which was 5.6\% according to the 2012 Global Adult Tobacco Survey. Even more worrisome is the evidence that most of the respondents were not aware of the textonly Health Warning Message found on cigarette packs and advertisements in Nigeria. Cigarette packs and Internet advertisement were reportedas sources of awarenessby most of them who were aware of the Health Warning Message. This is also worrisome considering the fact that these sources are mainly for the promotion of these products and not for dissuading people from smoking. According to Onyeonoro, Chukwuonye, Madukwe, Ukegbu, Akhimien and Ogah(2015), it is a well-known fact that sponsors of cigarette adverts and other promotional strategies do so to encourage the use of tobacco, rather than make it unacceptable to the public, hence, such strategies are designed to make smoking attractive, rather than make it unappealing and the inclusion of warning messages in the advert is basically in fulfillment of the mandatory requirement by the Federal Ministry of Health, in line with a global framework for tobacco control.

Regarding perceived dissuasiveness of the Health Warning Messages, majority of the respondents in the survey $(90.5 \% ; \mathrm{n}=361)$ perceived the text-only health message that warns that smokers are liable to die young as true. This is heartwarming as this perception is likely to dissuade nonsmokers from picking the habit and smokers from quitting. It is also heartwarming that majority of the respondents $90 \%(n=360)$ perceived this text-only Health Warning Message as likely to draw attention. According to McGuire (1989), attention isvital in the earliest stage of persuasion. For the scholar, if a message is successful with regards to 
DOI: doi.org/10.47851/naujocommed.v2i1.116

drawing attention in this earlystage, later-stage processes such as attitude and behaviour change may occur.

This study attempted to determine some factors that can influence perceived dissuasiveness andfindings show the content of the message as one of such. After exposure to two Graphic Health Warning Messages, 97\% of the respondents perceived them as likely to draw attention, while 3\% did not perceive them so. This shows that the Graphic Health Warning Messages (GHWMs) were perceived to be more likely to draw attention than the Text-only Health Warning Message. In addition, 83\% of the respondents perceived the GHWMs as likely to dissuade nonsmokers from picking the habit of smoking. Qualitative data from the Focus Group Discussion also showed that the perceived dissuasiveness of GHWMs is shared as most of them perceived them as likely to be more effective than the Text-only Health Warning Messages. This result confirms the content of the message as a factor that can influence perceived dissuasiveness and is consistentwith results from the study conducted by Mutti et al. (2016) which showed that graphic warnings were perceived to be more effective than text-only warnings. The qualitative data from the Focus groups which showed the participants perceiving the Graphic Health Warning Messages as more likely to be effectivesubstantiates these results. On the other hand, thequalitative data which showed that the participants in the two discussion groups were of the view that smokers have become accustomed to the Text-only Health Warning Message and have trained themselves to ignore them help explain why it may not have dissuasive enough.

Findings from this study also showed that smoking history is another factor that can influence perceived dissuasiveness of the text-only and Graphic Health Warning Messages. Results suggest that the more an individual smoked, the less the Text-only Health Warning Message was perceived as likely to draw attention as 6 out of 16 respondents who described themselves as occasional smokers, 3 out of 4 who described themselves as moderate smokers, and 11 out of the 12 who stated they were heavy smokers perceived the Text-only Health Warning Message as not likely to draw attention. However, of the respondents who described themselves as nonsmokers, only 20 out of 368 of them perceived the Text-only Health Warning Message as not likely to draw attention.

With regardto the perception of the Text-only Health Warning Message as likely to make smokers quit, only 1 out of the 12 respondents who described themselves as heavy smokers perceived it as likely to do so. This perception may be due to their experience that despite exposure to the Text-only Health Warning Message, they have not been able to quit smoking.

Smoking history was also shown to be a factor in the perceived dissuasiveness of the Graphic Health Warning Messages as likely to make smokers quit. Only 2out of those who described themselves as moderate smokers and just 1 out of those who stated they were heavy smokers perceived that the GHWMscould make smokers quit. Their perception gives a hint that the GHWMsare likely to have a boomerang effect on smokers. These findings are similar to those from the study conducted by Mansour and Bakhsh (2017) which showed that smokers generally perceived labels as significantly less effective compared with former smokers and nonsmokers. Qualitative data which showed that the smokers perceive the Health Warning Messages as exaggerated and unable to make smokers quit, gave a deeper insight into their perception. This perception that Health Warning Messages are exaggerated was also shared by the participants in Group 2 which consisted of nonsmokers, making the reasons why they may not make smokers quit the habit clearer. 
Generally, contrary to the findings from the study conducted by Ekwenchi and Ononiwu (2021), findings from this study showed that the smokers' perception was in line with their smoking behaviour. Stated differently, they did not perceive the Text-only Health Warning Message as dissuasive and have continued to smoke. This is different from findings from the study conducted by Ekwenchi and Ononiwu (2021) which showed a contrast between perception and behaviour, where some women had negative perception toward 'whitevertised' skincare products but went on to use them. However, the relationship between perception of Health Warning Messages on cigarette packs and smoking behaviour can be reassessed after the introduction of Graphic Health Warning Messages on cigarette packs in Nigeria. With this introduction, studies can be conducted to ascertain if the smokers have behaved in line with their perception that Graphic Health Warning Messages on cigarette packs can be dissuasive by changing their smoking habit.

The respondents' perception towards the text-only and Graphic Health Warning Messages is an indicationthat the effect of messages depends on individuals' disposition and the content of the message. Their perception also gives credence to empirical evidence from scholars like(Adebiyiet al. 2016; Fathelrahman et al., 2009; McCool et al., 2012; Thrasher et al., 2011; Peters et al., 2007; Strasser et al., 2012)that Graphic Health Warning Messages on the dangers of cigarette smoking are more dissuasive than those that are presented as text-only.

\section{CONCLUSION}

Based on the findings of this research, it is concluded that the perceived dissuasiveness of Health Warning Messages on the dangers of cigarette smoking depends on its content and the smoking history of individuals. Graphic Health Warning Messages are perceived to be more effective than the text-only because it is more likely to instil fear unlike the text-only which smokers have trained themselves to ignore. In addition, the more individuals smoke, the less they perceive these messages as dissuasive. In other words, the content of these messages and smoking history are factors that can influence perceived dissuasiveness. The perceived dissuasiveness of the text-only Health Warning Message is, therefore, an insight to why it may not be effective enough to make individuals desist from smoking, and that of those with graphics makes a case for Graphic Health Warning Messages on the dangers of cigarette smoking to be introduced in Nigeria.

\section{RECOMMENDATIONS}

The following recommendations are made based on the findings of this study:

1. The Federal Government should introduce Graphic Health Warning Messages and make them mandatory for cigarette packaging and any sort of cigarette advertisement. It can draw from WHO FCTC Health Warnings Database, a resource that contains 43 images that can be used by Parties to the WHO Framework Convention on Tobacco Control (FCTC) to dissuade people from tobacco use, in line with the Convention's Article 11 on 'Packaging and labelling' and Article 12 on 'Education and Public Awareness'.

2. The Graphic Health Warning Messages, when introduced, should be made to occupy 90\% of cigarette packs. This is to ensure they are noticed at first glance. While this may stir a boomerang effect on heavy smokers, it can be more effective than the textonly Health Warning Message in making occasional and moderate smokers quit the 
DOI: $\underline{\text { doi.org/10.47851/naujocommed.v2i1.116 }}$

habit. More so, it can dissuade nonsmokers who are in the majority from picking the habit.

3. A study of this nature should be replicated in other states since the present one is restricted to Anambra State. Other factors that can influence the perceived dissuasiveness of Health Warning Messages on the dangers of cigarette smoking should be the focus of these studies.

\section{REFERENCES}

Adebiyi, A. O., Uchendu, O. C.,Bamgboye, E., Ibitoye, O., \&Omotola, B. (2016) Perceived effectiveness of graphic health warnings as a deterrent for smoking initiation among adolescents in selected schools in southwest Nigeria. Tobacco Induced Diseases, 14, 7 DOI: 10.1186/s12971-016-0074-y

Canadian Cancer Society. (2014). Cigarette package health warnings: international status report. Canada.

Ekwenchi, C.O. \& Ononiwu, C.R. (2021). Perception and Health Risk Awareness of Whitevertised Skincare Products among Women in Anambra State, Nigeria. Nnamdi Azikiwe University Journal of Communication and Media Studies 2(1)

Fathelrahman, A.I., Omar, M., Awang, R., Borland. R., Fong, G.T., Hammond, D., \&Zain, Z. (2009) Smokers' responses toward cigarette pack warning labels in predicting quit intention, stage of change, and self-efficacy. Nicotine andTobacco Research 11(3), $248-253$.

Fishbein, M., \&Ajzen, I. (2010) Predicting and changing behavior: The reasoned action approach. New York, NY US: Psychology Press.

Fong, G.T. (2003) International Tobacco Control Policy Evaluation Project: Conceptual Foundation and Research Methods. Paper presented to the International Tobacco Control Research Team at the World Conference on Tobacco, Helsinki, Finland (August 2-8).

Fong, G.T., Hammond, D., \&Hitchman, S.C. (2009) The impact of pictures on the effectivenessof tobacco warnings.Bulletin of the World Health Organization, 87, 640643.

Freeman, M.A., Hennessy, E.V., Marzullo, D.M. (2001) Defensive evaluation of antismoking messages among college-age smokers: The role of possible selves. Health Psychology $20,424-433$

Hammond, D. (2009) Tobacco labelling and packaging toolkit: a guide to FCTC Article 11. Ontario, Canada: Tobacco Labelling Resource Centre

Hammond, D. (2011). Health warning messages on tobacco products: A review. Tobacco Control,20,327-337.

Hammond, D., Fong, G.T., McNeill, A., Borland, R., \&Cummings, K.M. (2006) Effectiveness of cigarette warning labels in informing smokers about the risks of 
DOI: doi.org/10.47851/naujocommed.v2i1.116

smoking: findings from the International Tobacco Control (ITC) Four Country Survey. Tobacco Control, 15,19-25.

Hiilamo, H., Crosbie, E., \&Glantz, S. A. (2014).The evolution of health warning labels on cigarette packs: The role of precedents, and tobacco industry strategies to block diffusion. Tobacco Control.23, e2.

Kees, J., Burton, S., Andrews, J.C., \&Kozup, J. (2006) Tests of graphic visuals and cigarette package warning combinations: implications for the Framework Convention on Tobacco Control. Journal of Public Policy \& Marketing, 25(2), 212-223

Kessels, L.T.E., Ruiter, R.A.C., \&Jansma, B.M. (2010) Increased attention but more efficient disengagement: Neuroscientific evidence for defensive processing of threatening health information. Health Psychology, 29, 346-354

MacKinnon, D.P., \&Fenaughty, A.M. (1993) Substance use and memory for health warning labels. Health Psychology 12: 147-150

Mansour, A.Y., \&Bakhsh, Z. (2017). Factors Affecting the Perceived Effectiveness of Pictorial Health Warnings on Cigarette Packages in Gulf Countries: A Crosssectional Study. Tobacco Use Insights.doi10 1179173X17698462

McCool, J., Webb, L., Cameron, L.D., \&Hoek, J. (2012) Graphic warning labels on plain cigarette packs: Will they make a difference to adolescents? Social Science and Medicine 74(8), 1269-1273

McGuire W. J. (1989).Theoretical foundations of campaigns. In Rice R. E., Atkin C. (Eds.), Public communication campaigns (2nd ed). Newbury Park, CA: SAGE

Mutti, S., Reid, J.L., Gupta, P.C., Pednekar, M.S., Dhumal, G., Nargis, N., Hussain, A.K.M.G., \&Hammond, D. (2016) Perceived effectiveness of text and pictorial health warnings for smokeless tobacco packages in Navi Mumbai, India, and Dhaka, Bangladesh: findings from an experimental study. Tobacco Control.Doi 10.1136/tobaccocontrol-2015-052315

Odeyemi, K.A., Osibogun, A., Akinsete, A.O., \&Sadiq, L. (2009). The prevalence and Predictorsof cigarette smoking among secondary school students in Nigeria. Nigerian Postgraduate Medical Journal, 16 (1),40-45

Onyeonoro, U.U., Chukwuonye, I.I., Madukwe, O.O., Ukegbu, A.U., Akhimien, M.O., \&Ogah, O.S. (2015) Nigerian Journal of Cardiology, 12(1), 27-33

Peters, E., Romer, D., Slovic, P., Jamieson., K.H., Wharfield, L., Mertz, C.K., Carpenter, S.M. (2007) The impact and acceptability of Canadian-style cigarette warning labels among U.S. smokers and nonsmokers. Nicotine \& Tobacco Research,9(4), 473-481

Rogers, R.W., \&Mewborn, C.R. (1976) Fear appeals and attitude change: Effects of a threat's 
DOI: doi.org/10.47851/naujocommed.v2i1.116

noxiousness, probability of occurrence, and the efficacy of coping responses. Journal of Personality and Social Psychology, 34, 54-61.

Ruiter, R.C., \&Kok, G. (2005) Saying is not (always) doing: Cigarette warning labels are useless. European Journal Public Health, 15(3), 329

Strasser, A.A., Tang, K.Z., Romer, D., Jepson, C., \& Cappella, J.N. (2012) Graphic warning Labelsin cigarette advertisements: Recall and viewing patterns. American Journal of Preventive Medicine,43, 41-47

Thrasher, J.F., Rousu, M.C., Hammond, D., Navarro, A., \&Corrigan, J.R. (2011). Estimating the impact of pictorial health warnings and "plain" cigarette packaging: Evidence from experimental auctions among adult smokers in the united states. Health Policy, $102,41-48$

World Health Organization (2002).Reducing Risks and Promoting Healthy Life. Geneva, Switzerland: World Health Organization

World Health Organization. (2013). WHO report on the global tobacco epidemic, 2013:

Enforcing bans on tobacco advertising, promotion and sponsorship. Geneva, Switzerland: World Health Organization

World Health Organization.(n.d.).WHO FCTC Health Warnings Database. Retrieved December 12, 2020 from http://www.who.int/tobacco/healthwarningsdatabase/en/.

\section{STIMULUS IMAGES}

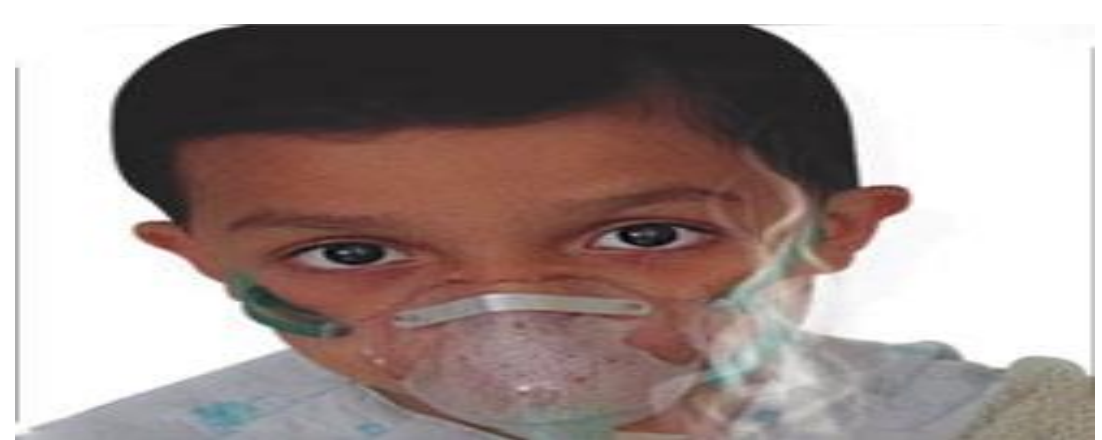

Fig 1.A Graphic Health Warning Message captioned 'Your smoke harms me' as available in Costa Rica (WHO, n.d.) 
NNAMDI AZIKIWE UNIVERSITY Journal of COMMUNICATTON AND MEDL STUDIES

Volume 2 Number 1 Jan-Mar Issue

ISSN:2756-486X (Online)

DOI: doi.org/10.47851/naujocommed.v2i1.116

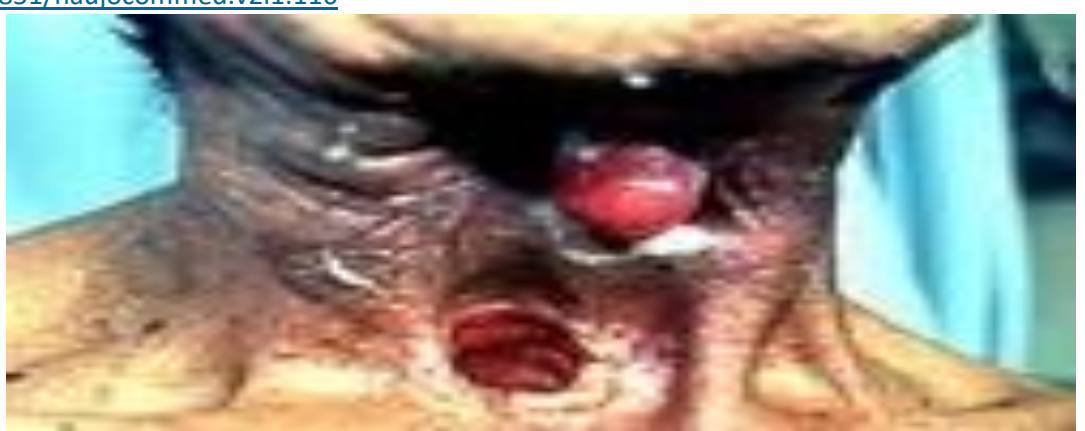

Fig 2.A Graphic Health Warning Message captioned'Cigarette causes neck cancer' as available in Malaysia (WHO, n.d.)

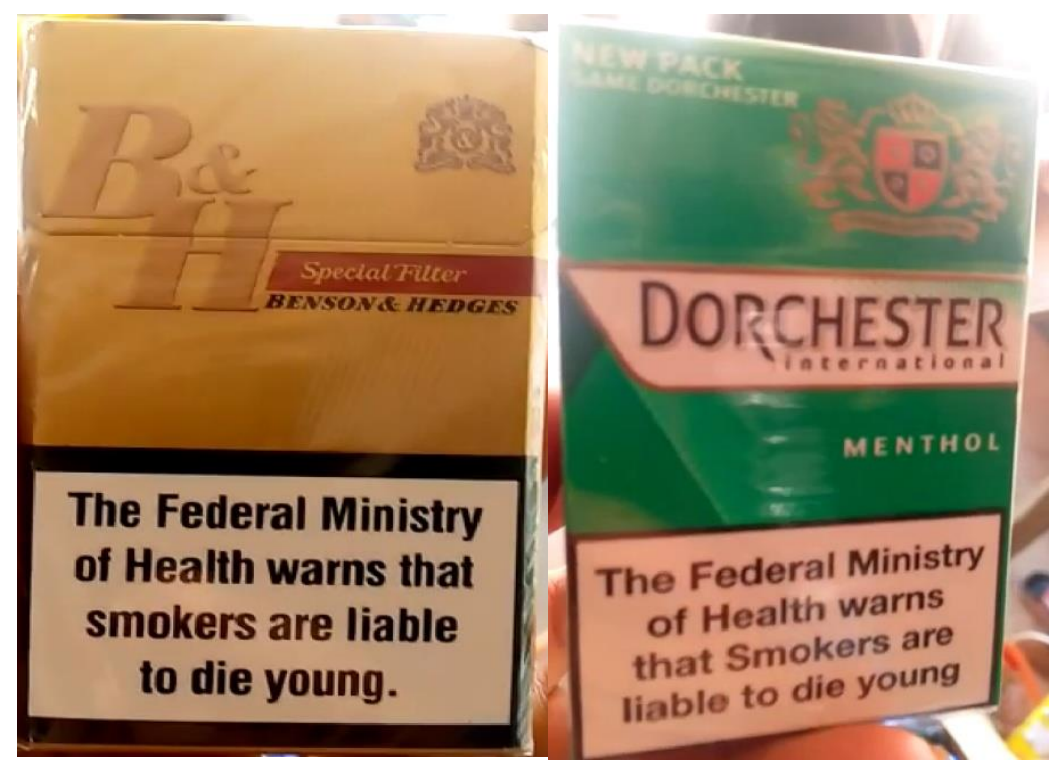

Fig 3. Benson and Hedges and Dorchester cigarette packs with Text-only Health Warning Message as available in Nigeria 